\title{
HUBUNGAN SOSIAL-POLITIK TAREKAT SAMANIYAH DENGAN KESULTANAN PALEMBANG DARUSSALAM
}

\author{
Ravico \\ Institut Agama Islam Negeri (LAIN) Kerinci \\ email: ravicoiainkerinci@gmail.com
}

\begin{abstract}
The Sammaniyah Order was the largest in the archipelago and became the driver of jihad fi sabilillah against the Dutch colonial. The involvement of the Sammaniyah Congregation in the political world has denied various views that claim the tarekat as the bearer of setbacks and chaos. This reason is the basis of this tarekat and political study. To find answers to the grand problem of the relationship between the Sammaniyah Congregation and the Palembang Darussalam Sultanate, historical research methods are used with steps such as heuristics, verification, interpretation and historiography. This study can conclude that between the Sammaniyah Congregation and the Palembang Darussalam Sultanate had a very close relationship the Palembang Darussalam Sultanate was the protector of the congregation in the sultanate region so that the religious system in Palembang would continue, while the Sammaniyah Congregation as the community elite became a driver of Islamic practice.
\end{abstract}

Keyword: : Sammaniyah Order, and Palembang Darussalam Sultanate

\begin{abstract}
Abstrak: Tarekat Sammaniyah merupakan terbesar di Nusantara dan menjadi pengerak jïhad fi sabilillah untuk melawan kolonial Belanda. Keterlibatan Tarekat Sammaniyah dalam dunia politik telah membantah berbagai pandangan yang menyatakan tarekat sebagai pembawa kemunduran dan kejumudan. Alasan inilah yang menjadi dasar kajian tarekat dan politik ini. Untuk menemukan jawaban dari grand problem tentang hubungan Tarekat Sammaniyah dengan Kesultanan Palembang Darussalam maka digunakan metode penelitian sejarah dengan langkah-langkahnya yaitu heuristik, verifikasi, interpretasi dan historiografi. Penelitian ini dapat simpulkan bahwa antara Tarekat Sammaniyah dengan Kesultanan Palembang Darussalam memiliki hubungan yang sangat erat Kesultanan Palembang Darussalam merupakan pelindung tarekat di wilayah kesultanan agar sistem keagamaan di Palembang tetap berjalan, sedangkan Tarekat Sammaniyah sebagai elit masyarakat menjadi penggerak dari pengamalan agama Islam.
\end{abstract}

Kata Kunci: Tarekat Sammaniyah, dan Kesultanan Palembang Darussalam 


\section{PENDAHULUAN}

Masuknya Islam di Nusantara masih menjadi diskusi panjang yang belum terselesaikan. Teori kedatangan Islam yang dikemukakan oleh Crawfrud menyatakan bahwa Islam dikenalkan pada masyarakat Nusan-tara langsung dari tanah Arab pada abad ke 7. ${ }^{1}$ Teori ini juga didukung oleh Uka Tjandrasasmita dan Syed Naquib Al-Attas, dimungkinkan orangorang Islam dari Arab, Persia, India sudah banyak berhubungan dengan orang-orang di Asia Teng-gara dan Asia Timur. ${ }^{2}$

Hal ini dibuktikan dengan adanya jalur perdagangan inter-nasional kala itu antara Dinasti Tang di Cina, Kerajaan Sriwijaya di Asia Tenggara dan Dinasti Ummayah di Asia Barat. Teori berbeda yang ditulis oleh Snouck Hurgronje menurutnya kedatangan Islam terjadi pada abad ke 13 dari Gujarat dengan ditemukannya bukti makam sultan Islam pertama Sultan Malikus Saleh seorang raja pertama Kerajaan Samudera Pasai.

Kedua teori tersebut memiliki landasan masing-masing dalam menyoroti kedatangan Islam. Dari kedua teori di atas menurut penulis dapat digunakan pendekatan eko-nomi dan politik untuk menjawab perdebatan panjang tersebut. Islam dapat dikatakan masuk pada abad ke 7. Namun Islam dalam abad ini, baru masuk belum menjadi basis koloni dan agama rakyat. Pada abad ini, hubungan ekonomi antara Dinasti Ummayah dengan Kerajaan Sri-wijaya, secara tidak langsung mengenalkan Islam ke Nusantara. Sebelum abad ke 13, Islam mulai berkembang, banyak rakyat yang memeluk Islam. Kehidupan sosial masyarakat mulai dipengaruhi oleh ajaran-ajaran Islam. Islam mulai menunjukan kekuatan politik terbesar di Nusantara.

Setelah menjadi kekuatan politik yang tangguh, pada Abad ke 13 Islam telah mampu mendirikan organisasi pemerintahan yang kemudian dikenal sebagai kesultanan dan menjadikan Islam sebagai agama resmi kesultanan, itu artinya Islam telah menjadi agama rakyat. Pernyataan di atas sejalan dengan pendapat Taufik Abddullah yang membagi proses Islamisasi dalam tiga fase yaitu de kosm (datang) dipengaruhi motif ekonomi, receptive (penerimaan) didorong oleh motif agama dan uitbreiding (pengembangan) didorong oleh motif politik. $^{3}$

\footnotetext{
hlm. 36.

${ }^{1}$ Huda, Nor. 2007. Islam Nusantara: Sejarah Sosial Intelektual Islam Indonesia. Yogyakarta: Ar-Ruzz Media,

2 Tjandrasasmita, Uka. 2007. Pertumbuban dan Perkembangan Kota-kota Muslim di Indonesia: dari Abad XIII Sampai XVII Masehi. Kudus: Menara Kudus, hlm. 17.

3 Abdullah, Taufik. 1979. Agama, Etos Kerja dan Perkembangan Ekonomi. Jakarta:1979, hlm. 1.
} 
Sejak masuk dan berkembangnya, Islam memerlukan proses yang sangat panjang dan melalui saluran-saluran Islamisasi yang beragam, seperti perdagangan, perkawinan, tarekat (tasawuf), pen-didikan dan kesenian. Tasawuf menjadi sorotan penting peneliti dalam penulisan ini. Tasawuf juga menjadi penting dalam proes Islamisasi di Indonesia. Taswuf termasuk kategori media yang berfungsi dan membentuk kehidupan sosial bangsa Indonesia yang meninggalkan banyak bukti jelas berupa naskah-naskah antara abad 13 dan abad $18 .{ }^{4}$

Secara historis, pemaknaan lafaz tarekat berkembang dan berbanding lurus dengan sejarah perkembangan tasawuf, karena di antara keduanya terdapat hubungan yang bersimbiosis yang tidak dapat dielakan. Pada mulanya tarekat dimaknai sebagai jalan spiritual (batiniah) yang dikhususkan bagi mereka yang ingin melakukan upaya pendekatan diri kepada Allah dan pencapaian hakikat, dengan harapan memperoleh kemajuan dalam tingkatantingkatannya. Dengan de-mikian, tarekat adalah paduan khas dari dokrin, metode dan ritual dan hanya berlaku pada tataran personal. ${ }^{5}$

Selama ini, tarekat dan tasawuf dipahami sebagai ajaran yang mendatangkan kejumudan dan kemunduran. Kehidupan tarekat diidentikan dengan kehidupan menderita, kehidupan yang menghindari dunia dan tidak mau terlibat dalam kehidupan masyarakat. Pandangan ini telah banyak diluruskan oleh para ulama seperti Hamka dengan tasawuf moderennya, dan Fazlur Rahman dengan neo-sufismenya. ${ }^{6}$

Sedangkan Azra dalam karyanya yang berjudul Jaringan Ulama Timur Tengah dan Kepulauan Nusantara Abad ke XVII dan XVIII memberikan pandangan baru, menurutnya:

"Tuduban kaum modernis bahwa tasawuf mendorong kepasifan dan penarikan diri dari permasalaban dunia hanya didasarkan terutama kepada ketidaktabuan dan kekeliruan pengertian tentang keseluruban ajaran tasawnf. Saya telah membuktikan sepanjang bahwa take seorang pun di antara para tokoh kita dalam jaringan ulama mengajarkan kepasifan dan penarikan diri. Sebaliknya mereka menghimbau kaum Muslim agar aktif. Bagi mereka pemenuban kewajiban dunaiawi kaum Muslim merupakan bagian integral dari kemajuan spiritual dalam perjalanan mistis." '

Dalam kasus para ulama Melayu-Indonesia pada abad ketujuh belas, ulama seperti alRaniri, al-Sinkili dan Maqasari menampilkan diri mereka sebagi sufi-sufi teladan, yang memberikan perhatian bukan hanya kepada perjalan spiritual mereka sendiri melainkan juga

\footnotetext{
${ }^{4}$ Huda, Nor, Op., Cit., hlm. 44.

5 Al-Kaf, Idrus. 2008. Tarekat dan Pemberdayaan Ekonomi Umat: Studi tentang Pemberdayaan Ekonomi Umat Tarekat Idrisiyah Pegendingan Tasikmalaya, dalam distertasi. Jakarta: UIN Syarif Hidayatullah, hlm. 42.

${ }^{6}$ Al-Kaf, Idrus, Ibid., hlm. 49

7 Azra, Azyumardi,1994. Jaringan Ulama Timur Tengab dan Kepulauan Nusantara Abad XVII dan XVII: Melacak. Akar-Akar Pembaharuan Pemikiran di Indonesia. Bandung:Mizan, hlm. 282.
} 
masalah dan tugas duniawi, dengan memegang jabatan sebagai mufti di kesultanan masingmasing. ${ }^{8}$ Sehingga pemikiran mengenai jihad melawan kolonial lebih tercurahkan.

Anjuran tentang jihad, justru datang dari Al-Palembani dan Al-Fatani, yang melewatkan sebagian besar hidup dan meninggal di Haramayin. Ini adalah bukti kuat ketertarikan sangat erat dan kepedulian mereka yang begitu besar pada Islam di tanah air mereka. Ini menunjukan, mereka bukanlah sufi yang digambarkan kaum modernis, yang hanya disibukan dengan urusan spiritual mereka dan terasing dari masyarakat mereka pada umumnya. Ini juga mengisyaratkan, kontak dan komunikasi antara wilayah Melayu-Indonesia dengan Haramayin dapat dipertahankan dengan baik, sehingga para ulama Jawi mendapat informasi memadai mengenai perkembangan Islam di Nusantara, terutama dalam kaitannya dengan penetrasi yang terus menerus dilakukan kaum kafir. ${ }^{9}$

Pada masa kolonial, tarekat pun tampil sebagai gerakan perlawanan untuk memerangi penjajah. Sejarah mencatat, ada sejumlah gerakan perlawanan besar yang dilakukan para tokoh tarekat dan pengikutnya di Nusantara. Menurut Azyumardi Azra, respons Muslim pribumi terhadap penjajah Belanda terbagi menjadi dua kelompok, ada yang melakukan perlawanan secara terbuka dan ada pula yang melakukan perlawanan secara tertutup. Para kiayi dan pengikutnya melakukan perlawanan dengan metode 'u§lah' yaitu menjauhkan diri dari penguasa kolonialis yang kafir. Uzlah para ulama itulah yang kemudian telah mendorong terjadinya radikalisasi para pengamal tarekat. yang kemudian menjadi perang anti-kolonialisme, salah satunya dimotori tarekat tasawuf yang berkembang waktu itu. ${ }^{10}$

Sebagai contoh, peperangan Kesultanan Palembang Darussalam melawan kolonial tahun 1819 yang juga kelompok tarekat terlibat di dalamnya hal ini tergambar dalam Syair Perang Menteng. Dalam syair perang menteng tidak disebutkan tarekat apa yang menggerakan masyarakat Palembang melakukan perlawanan terhadap kolonial namun dilihat dari ritual dan amalan yang diajarakan merupakan Tarekat Sammaniyah. ${ }^{11}$

Menurut Bruinessen, Tarekat Sammaniyah yang berkembang di Palembang dibawa dari tanah suci oleh murid-murid Abdussamad al-Palimbani pada penghujung abad ke-18. Syaikh Abdussamad dikenal terutama sebagai pengarang Sya'ir Al-Salikin dan Hidayat AlSalikin, dua karya sastra tasawwuf Melayu yang penting. Dua karya ini berdasarkan Ibya dan Bidayat Al-Hidayah- Al-Ghazali, dengan tambahan bahan dari berbagai kitab tasawuf lainnya.

8 Azra, Azyumardi, Ibid., hlm. 282.

${ }^{9}$ Azra, Azyumardi, Ibid., hlm. 283.

10 Azra, Azyumardi, Ibid., hlm. 282.

11 Bruinessen, Martin Van. 1995. Kitab Kuning: Pesantren dan Tarekat. Badung: Mizan, hlm. 331. 
Syaikh Abdus-samad, papar Bruinessen, adalah seorang sufi yang tidak mengabaikan urusan dunia, bahkan mungkin boleh disebut militan. Tidak mengherankan kalau murid-muridnya yang ahli tarekat juga siap untuk berjihad fisik. ${ }^{12}$

Jika dilihat dari keterlibatan Tarekat Sammaniyah dalam perang menteng ini menandakan adanya ikatan yang erat antara kelompok tarekat dengan Kesultanan Palem-bang. Sultan Palembang me-miliki peranan penting sebagai pelindung Tarekat Sammaniyah. ${ }^{13}$

Karena itulah mendorong penulis melakukan studi analisis secara khusus terhadap hubungan Tarekat Sammaniyah dengan Kesul-tanan Palembang. Dari uraian pemikiran dan gejala sejarah di atas dapat penulis rumuskan permasalahan yaitu: 1) bagaimana sejarah perkem-bangan Tarekat Sammaniyah di Palembang?; dan 2) bagaimana hubungan Tarekat Sammaniyah dengan Kesultanan Palembang Darussalam?

\section{METODE}

Dalam penelitian ini yang menjadi objek penelitian adalah teks-teks tertulis yang menerangkan atau mengandung gagasan tertentu. Dengan demikian jenis data yang digunakan adalah data kualitatif. Data kualitatif dalam penelitian ini merupakan prosedur penelitian yang menghasilkan data deskriptif yang berupa data-data tertulis. ${ }^{14}$ Karena itu, berdasarkan jenis data dan tema penelitian yang akan digarap maka jenis penelitian ini merupakan penelitian pustaka (library reseach).

Dalam penelitian ini, sumber primer yang digunakan berupa dokumen-dokumen yang mencatat peristiwa seperti naskah Syair Perang Menteng dan Nasihat al-Muslimin wa tadqkirat alMu'min fi Fadha'il al-Jibad fi Sabilillah wa Karaman al-Mujabidin fi Sabilillah (Nasihat dan Peringatan bagi Kaum Muslimin yang Beriman tentang Keutamaan Jihad dan Kemuliaan Mereka yang Berjihad). Sedangkan sumber se-kunder yang digunakan adalah semua bahan ditulis di jurnal, koran, buku teks yang berkaitan langsung dengan penelitian. Penelitian ini merupakan penelitian sejarah dengan langkah-langkahnya yaitu heuristik, verifikas, interpretasi dan historiografi.

12 Bruinessen, Martin Van, Ibid., hlm. 334.

${ }^{13}$ Yani, Zulkarnain. 2011. 'Al-Urwah al-Wuthqa: Tradisi dan Ritual Tarekat Sammaniyah diPalembang.Jakarta: Penamadani., hlm. 103.

${ }^{14}$ Moleong, J.Lexy. 2001. Metodologi Penelitian Kualitatif. Bandung: Remaja Rosdakarya, hlm. 3. 


\section{HASIL PENELITIAN DAN PEMBAHASAN}

\section{Perkembangan Tarekat Sammaniyah di Palembang}

Awal penyebaran Tarekat Sammaniyah di Palembang tidak terlepas dari peranan keraton Kesultanan Palembang Darussalam. Hal ini dapat dilihat dari berbagai sumber tertulis. Hubungan keraton Kesultanan Palembang Darussalam dengan Tarekat Sammaniyah di mulai dengan hubungan beberapa ulama Palembang yang pergi ke Makkah yang menuntut ilmu, diataranya Syaikh Muhammad Aqib Ibn Kgs. Hasan al-Din (1736-1818M). dan berkenalan dengan ulama Palembang yang terkenal yaitu Syaikh Abdul Shamad al-Palembani. ${ }^{15}$

Syaikh Abdul Shamad al-Palembani (1704-1789 M) adalah murid Syaikh Muhammad Samman yang paling terkenal dan paling besar pengaruhnya dalam penyebaran tarekat Sammaniyyah di Nusantara (Zulkifli dan Nasution,2001:74). Abdul Shamad al-Palembani adalah putra Syaikh Abdul al-Jalil bin Syaikh Abd al-Wahab bin Syaikh Ahmad al-Madani dari Yaman, seorang Arab yang setelah tahun 1112 H/ 1700 M diangkat menjadi mufti negri Kedah. ${ }^{16}$

Pengaruh Syaikh Muhammad Samman terhadap Abdul Shamad al-Palembani sangat besar dan pengaruh tersebut jauh lebih besar dibanding-kan pengaruhnya terhadap muridmurid asal Nusantara lainnya. Bahkan, ajaran-ajaran kesufian Syaikh Muhammad Samman sangat mewarnai perkembangan corak pemikiran keagamaan Abdul Shamad al-Palembani. Dalam dua karyanya yang paling utama, Sayir al-Salikin dan Hidayah al-Salikin, meskipun sebagian besar merupakan terjemah karya Al-Ghazali, Abdul Shamad Al-Palimbani memasukkan ajaran Tare-kat Sammaniyyah dan informasi tentang lingkungan intelektual Syaikh Muhammad Samman. ${ }^{17}$

Berkat usaha dan karya Abdul Shamad al-Palembani tarekat Sammaniyyah berkembang di beberapa wilayah di Nusantara. Qizwan menyimpulkan bah-wa Abdul Shamad al-Palembani adalah ulama Nusantara yang pertama kali memperkenalkan ajaran -ajaran sufisme Syaikh Muhammad Samman ke dalam kitab-kitab ber-bahasa Melayu. Abdullah juga menyatakan bahwa Abdul Shamad al-Palembani adalah orang pertama yang menyebarkan Tarekat Sammaniyah di Nusantara dan karena pesatnya perkembangan tarekat, ia dianggap sebagai "se-orang propagandis ulung di bidang sufi dan Thariqatnya". Syaikh Abdul Shamad tidak hanya terkenal sebagai guru Tarekat Sammaniyah tapi juga diketahui sebagai ulama dan sufi

15 Yani, Zulkarnain, Op., Cit., hlm. 101-102.

16 Arsyad dalam KHO Gadjahnata, Sri dan Edi Swasono. 1968. Masuk dan Berkembangnya Islam di Sumatera Selatan. Jakarta; UIN Press, hlm. 178.

${ }^{17}$ Solihin. 2005. Melacak Pemikiran Tasawuf di Nusatara. Jakarta: Raja Grafindo Persada, hlm. 99. 
Nusantara yang memiliki wawasan intelektual yang luas. Ia mengadakan penyesuaian antara inti ajaran wabdah al-wujud Ibnu 'Arabi dan prinsip-prinsip ajaran sufisme Al-Ghazali. Inti ajaran tersebut olehnya, diletakkan sebagai dua tingkatan pengamalan kesufian yang berbeda namun saling melengkapi, yang harus dicapai oleh seorang sufi. ${ }^{18}$

Sebagai ulama dan sufi asal Palembang, Abdul Shamad al-Palembani tentu saja memiliki andil besar dalam penyebaran ajaran Tarekat Sammaniyah di Palembang dan daerahdaerah lain di Sumatera Selatan. Tidak sedikit murid asal Sumatera Selatan yang berguru kepadanya dan kemudian menjadi ulama dan guru tarekat Sammani-yyah. Karya-karyanya juga beredar secara luas dan bahkan masih dibaca dan diajarkan hingga saat ini.

Selain Abdul Shamad al-Palembani terdapat paling tidak dua ulama Palembang yang berguru langsung kepada Syaikh Muhammad Samman. Mereka itu adalah Muhammad Muhy al-Din bin Syihab al-Din dan Kemas Muhammad bin Ahmad. ${ }^{19}$

Keduanya dianggap memiliki andil dalam penyebaran Tarekat Sammaniyah di Palembang. Keterli-batan keduanya dalam penyebaran tarekat dimaksudkan dengan karya yang ditulisnya. Sebagaimana di-sebutkan sebelumnya, Muhammad Muhy al-Din menerjemahkan kitab Al-Manaqib al-Kubra ke dalam bahasa Melayu dengan Judul Hikayat Syaikh Muhammad Samman yang selesai ditulis tahun 1791 M. Sedang Kemas Muhammad bin Ahmad menulis kitab Nafahat al-Rahman Manaqib Uztadzina al-A'ram al-Samman. ${ }^{20}$

Salah seorang murid Abdul Shamad al-Palembani yang tekenal dan memiliki andil besar dalam penyebaran Tarekat Sammaniyah di Palembang adalah Muhammad Aqib bin Hasan al-Din. Ia lahir di Palembang sekitar tahun $1760 \mathrm{M}$ dan pada usia muda berangkat ke Makkah dan melanjutkan studi agama dengan Abdul Shamad al-Palembani. ${ }^{21}$ Dari gurunya Abdul Shamad Al-Palembani, ia mendapatkan ijazah untuk mengajarkan dan mengembangkan Tarekat Sammaniyah. Setelah kembali ke Palembang, dia menetap di Kampung Pangulon, di belakang Masjid Agung yang berdekatan dengan keraton Palem-bang. Syaikh Muhammad Aqib memiliki hubungan yang erat dengan pihak kesultanan. Bahkan setelah kesultanan runtuh (1923 M), Muhammad Aqib tetap menjalin kerjasama dengan kaum ningrat keraton, khususnya Panembahan Bupati, saudara laki-laki Sultan Mahmud Badrudin II dan sunan Ahmad Najamudin II, yang bertindak sebagai pelindung Agama. Tetapi terlepas dari keterlibatannya dalam bidang politik dan hubungan erat dengan mantan pembesar keraton,

18 Zulkifli dan Abdul Karim Nasution. 2001. Islam dalam Sejarah dan Budaya Masyarakat Sumatera Selatan. Palembang: Universitas Sriwijaya, hlm. 76.

${ }^{19}$ Quzwain dalam KHO Gadjahnata, Sri dan Edi Swasono, Op., Cit., hlm. 176.

${ }^{20}$ Zulkifli dan Abdul Karim Nasution, Op., Cit., hlm. 77-78.

21 Yani, Zulkarnain, Op., Cit., hlm. 102. 
Syaikh Muhammad Aqib adalah ulama dan guru Tarekat Sammaniyah yang di segani masyarakat. ${ }^{22}$

Dengan demikian Syaikh Muhammad Aqib bertanggung jawab terhadap penyebaran Tarekat Sammaniyah di Palembang. Berbagai silsilah menyebutkan nama Syaikh Muhamad Aqib yang menerimanya dari Syaikh Abdul Shamad al-Palembani. ${ }^{23}$ Dia tentu saja memiliki sejumlah murid terkenal yang juga berperan penting dalam pengajaran agama Islam dan penyebaran tarekat Sammaniyah. Di antara muridnya yang terkenal adalah Abdullah bin Ma'ruf dan anaknya sendiri, Hasanudin bin Muhammad Aqib. Ulama-ulama lain yang diduga menjadi murid Syaikh Muhammad Aqib adalah Muhammad Azhary bin Abdullah bin Ahmad, Masagus Haji Abdul Hamid bin Mahmud, dan saudaranya Masagus Haji Abdul Aziz bin Mahmud. ${ }^{24}$

Syaikh Abdul Shamad al-Palembani juga pernah menunjuk menantunya, Kemas Haji Muham-mad Zain, sebagai guru tarekat Sammaniyyah. Syaikh inilah yang telah menurunkan ajaran tarekat tersebut hingga sampai kepada ayah K.H. Amin Azhari. Kyai Amin yang menerima ijazah dari ayahnya itu sekarang tidak lagi mengajarkan tarekat Sammaniyah. Di ketahui juga bahwa Kemas Muhammad Zain menjadi pemimpin dalam perang melawan pasukan Belanda pada tahun 1819 M yang dikenal dengan perang Menteng. Hal ini tertulis dalam "Syair Perang Menteng” sebagai berikut:

$\cdots$

Diikeutlah segala haji garang

Haji Zain kepalanya sekarang

Itulah mula jadi berperang

Di kota lama sampai di serang (bait no.13)

Dalam catatan sejarah Kesultanan Palembang Darussalam tahun 1819 M telah terjadi peperangan antara pengikut Tarekat Sammaniyah dan pasukan Belanda. ${ }^{25}$

Dari fenomena di atas, jika dikaji lebih dalam mengenai hubungan antara Kesultanan Palembang Darus-salam dengan Tarekat Sammaniyah dapat digunakan teori pertukaran soasial. Dalam Teori pertukaran sosial ini didasarkan pada pemikiran bahwa seseorang dapat

22 Peeters, Jeroen. 1997. Kaum Tuo-Kaum Mudo: Socaial Religieuze Verandering in Palembang. Terj. Sutan Maimoen. Jakarta: INIS., hlm. 24.

23 Peeters, Jeroen, Ibid, hlm. 24.

${ }^{24}$ Zulkifli dan Abdul Karim Nasution, Op., Cit., hlm. 81. hlm. 14.

${ }^{25}$ Hanaifah, Johan, 1999. Melayu-Jawa; Citra Budaya \& Sejarah Palembang. Jakarta: Raja Grapindo Persada., 
mencapai satu pengertian mengenai sifat kom-pleks dari kelompok dengan mengkaji hubungan di antara dua orang (dydic relationship). Suatu kelompok dipertimbangkan untuk kumpulan dari hubungan antara dua partisipan tersebut. Perumusan tersebut mengasumsikan bahwa inte-raksi menusia melibatkan pertukaran barang dan jasa, dan bahwa biaya (cost) dan imbalan (reward) di-pahami dalam situasi yang akan disajikan untuk mendapatkan respon dari individu-individu selama inte-raksi sosial. ${ }^{26}$

Hubungan keduanya tampak bersimbiosis, Kesultanan Palembang berhubungan dengan tarekat Sammaniyah untuk memperkuat pertahanan wilayahnya, karena telah diketahui bahwa Tarekat Sammaniyah meru-pakan kelompok elit masyarakat yang memiliki kekuatan besar di masyarakat. Selain itu, kharismatik seorang mursyid (guru) melebihi seorang sultan. Sedangkan Tarekat Sammaniyah menjadikan Kesultanan Palembang sebagai pelindung dan wadah politiknya untuk melawan kolonial.

Selanjutnya, Muhammad Azhary bin Abdullah bin Ahmad (1811-1874M), yang mempelajari Tarekat Sammaniyah dan mendapat ijazah dari Syaikh Muhammad 'Aqib. Meskipun wafat di Makkah, guru tarekat ini melaksanakan pendidikan, pengajaran dan dakwah Islam di Palembang lebih dari tiga puluh tahun sehingga memiliki banyak murid baik dari ibukota Palembang maupun dari daerah pedalaman. Dia dikenal sebagai ula-ma yang menguasai ilmu tauhid dan falaq. ${ }^{27}$

Muhammad Azhary bin Abdullah bin Ahmad kemudian memberikan ijazah Tarekat Sammaniyyah kepada putranya, Haji Abdullah bin Muhammad Azhary (1854-1974M). Haji Abdullah Azhary dikenal sebagai ulama yang menguasai ilmu fiqih, tauhid, tasa-wuf, dan falaq yang dipelajarinya di Palembang dan di Makkah. Setelah kembali dari Makkah, ia menetap di tanah kelahirannnya sekitar 12 Ulu untuk melanjutkan kegiatan pendi-dikan dan pengajarannya yang sudah dirintis oleh ayahnya. Karena keakti-vasnnya dalam menyelenggarakan pengajaran dan dakwah Islam, Haji Abdullah Azhary menjadi tokoh yang sanggat disegani oleh masyarakat. Ia senantiasa memberi-kan bimbingan dan pelayanan kepada masyarakat dan terus memimpin berbagai ritual dan perayaan agama maupun kegiatan-kegiatan tarekat Sammaniyah hingga usia sepuh. Oleh karena itu, Haji Abdullah Azhary dikenal dengan sebutan Ki Pedatukan dan kampungnya disebut kampung Pedatukan. Akan tetapi, aktivitas Ki Pedatukan dalam bidang pengajaran dan dakwah Islam dan penyebaran Tarekat Sammaniyah ti-dak hanya terbatas di kampungnya tetapi juga di daerah-daerah pedesaan di Sumatera Selatan. ${ }^{28}$

\footnotetext{
${ }^{26}$ Andy.tt:3 dalam jbptuni-kompp-gdl-andinurulh-23207-6-6te-ori-pdf di-akses pada 16 Desember 2017

${ }^{27}$ Zulkifli dan Abdul Karim Nasution, Op., Cit., hlm. 16.

28 Zulkifli dan Abdul Karim Nasution, Ibid., hlm. 83.
} 
Guru Tarekat Sammaniyah lainnya adalah Masagus Haji Abdul Hamid bin Mahmud (1811-1901 M) yang lebih dikenal dengan sebutan Kyai Marogan atau Ki Marogan. Dia di perkirakan mempelajari Tarekat Sammaniyah dari orang tuanya sen-diri, yakni Masagus Haji Mahmud bin Kanan, salah seorang murid Syaikh Abdul Sammad, atau mung-kin juga mendapat ijazah tarekat dari Syaikh Muhammad Aqib. Berbeda dengan Muhammad Azhary bin Abdullah bin Ahmad, Haji Abdullah Hamid tidak meninggalkan karya tulis yang di publikasikan kecuali Naskah Jadwal Waktu Sholat Lima Waktu dan Naskah Daftar Surat-Surat yang Dibaca Waktu Sholat Lima Waktu yang terdapat di Masjid Agung Palembang. Tapi menurut keturunanya, Ki Marogan pernah menulis kitab tasawuf.

Sementara Ki Marogan terkenal sebagai ulama dan guru tarekat yang berhasil dalam bidang ekonomi. Dia mendirikan dan mewakafkan dua masjid di Palem-bang, yaitu Masjid Jami’ Kiai Haji Abdul Hamid bin Mahmud yang di kenal dengan sebutan Masjid Ki Marogan dan Masjid Mujahidin atau Masjid Lawang Kidul. Murid dan sekaligus teman dekat yang belakangan menjadi guru Tarekat Sammaniyah adalah Haji Abdur-rahman Delamat (1820-1895M) yang dikenal dengan pangilan Ki Delamat. Seperti Ki Marogan, Ki Delamat banyak memprakarsai pendirian masjid di daerah-daerah pedalaman Sumatera Selatan. ${ }^{29}$

Murid Syaikh Muhammad Aqib yang lain adalah Abdullah bin Ma'ruf kemudian memberikan ijazah Tarekat Sammaniyah kepada murid-nya, Muhammad Azhary bin Abdullah bin Asikin (1856-1934 M). Guru tarekat ini adalah ulama Palembang yang paling produktif menulis karya-karya ke-Islaman sete-lah Syaikh Abdul Shamad Al-Palembani. Haji Abdullah Azhary bin Abdullah bin Askin ini yang memberikan ijazah kepada menan-tunya, Hasan bin Abdul Syukur dan yang terakhir kepada anaknya. ${ }^{30}$

\section{Hubungan Tarekat dengan Kesultanan Palembang}

Peran Tarekat Sammaniyah dalam gerakan dapat dilihat dari seberapa jauh hubungan Tarekat Sammaniyah dengan Kesultanan Palembang. Hubungan antara Kesul-tanan Palembang dengan Tarekat Sammaniyah dimulai dengan hu-bungan beberapa ulama Palembang yang pergi ke Makkah untuk me-nuntut ilmu di sana, diantaranya Syaikh Muhammad Aqib Ibn Kgs Hasan al-Din (1736-1818) ia berguru kepada Syaikh Abdul Shamad Al-Palembani. ${ }^{31}$

${ }^{29}$ Zulkifli dan Abdul Karim Nasution, Ibid., hlm. 84-85.

${ }^{30}$ Zulkifli dan Abdul Karim Nasution, Ibid., hlm. 85-86.

31 Yani, Zulkarnain, Op., Cit., hlm. 102. 
Setelah menimba ilmu di Makkah Syaikh Muhammad Aqib Ibn Kgs Hasan al-Din pulang ke Palembang dan menetap di Kampung Penghulon, di Belakang Masjid Agung yang langsung berdekatan dengan keraton. Ada beberapa petun-juk yang membenarkan pandangan adanya hubungan erat antara sultan Palembang dengan Tarekat Samma-niyah. Peeters Menyebutkan bahwa ada dua petunjuk yang menandakan penyebaran Tarekat Sammaniyah di Palembang dan mendapatkan perhatian yang sangat istimewa dari Sultan Palembang, antara lain pertama dijumpai dalam versi Palembang Hikayat Syaikh Muhammad Saman. ${ }^{32}$ Di dalamnya disebutkan bah-wa sebuah qawiah Tarekat Sammaniyah yang didirikan di Jeddah oleh Sultan Mahmud Baha’uddin sebagai wakafnya pada tahun 1776 dengan menggunakan pemberian mulia 500 real. Jeddah merupakan pelabuhan terpenting untuk jemaah haji dalam perjalanan ke Mekkah, zawiyah ini sekaligus berfungsi sebagai peng-inapan jema-ah dari Palembang dalam perjalanan mereka menuju kota suci. Kedua, hubungan antara keraton dan Sammaniyah dijumpai dalam bentuk naskah yang berasal dari keraton Palembang. Dalam terjemahan bahasa Melayu Bahr al-Ajaib di da-lamnya disebutkan nama pengarang-nya yaitu Kemas Muhammad Ibn Kemas Ahmad yang menulis naskah ini atas perintah Sultan Mahmud Badarudin, yang menulis naskah tentang Hikayat Kramat Shekh Muhammad Samman. ${ }^{33}$

Dari data ini dapat disimpul-kan bahwa para sultan Palembang mempunyai peranan penting sebagai pelindung Sammaniyah. Runtuhnya keraton pada tahun 1821, mengakhiri pula hubungan erat antara negara dan agama. Akan tetapi, runtuhnya kesultanan bukan berarti bubarnya Tarekat Sammaniyah. Untuk ningrat Palembang, tarekat ini justru menjadi kerangka alternatif pengganti masyarakat keraton. Fungsi sosial sesudah 1821 terutama dikem-bangkan oleh Panembahan Bupati, saudara lelaki Sultan Mahmud Nadjamuddin II, yang diizinkan tinggal di Palembang. ${ }^{34}$

Melalui Shaykh Muhammad Aqib Ibn Kgs. Hasan al-Din inilah hubungan keraton Palembang dan Tarekat Sammaniyah terus terjalin melalui jalinan kerjasama dengan Panembahan Bupati dan Sunan Ahmad Nadjamuddin II yang ber-tindak selaku pelindung agama. Terlepas dari keterlibatannya dalam bidang politik dan hubunganya yang erat dengan mantan pembesar ke-raton, Sheykh Kiagus Muhammad Aqib adalah ulama dan guru Tarekat Sammaniyah yang disegani mas-yarakat. Di dalam laporan Belanda tahun 1834 M disebutkan bahwa dia adalah guru agama (di bidang hukum Islam) dengan jumlah murid terbesar di Palembang.

\footnotetext{
32 Peeters, Jeroen, Op., Cit, hlm. 23.

${ }^{33}$ Zulkifli dan Abdul Karim Nasution, Op., Cit., hlm. 79.

${ }^{34}$ Peeters, Jeroen, Op., Cit, hlm. 24.
} 
Kemudian pada tahun 1840-an namanya muncul lagi ketika perayaan agama yang dibiayai oleh Panembahan Bupati sehingga me-nimbulkan kecurigaan Belanda yang melihat ritual ini hanya sebagai kedok bagi pada pengikut Panem-bahan agar dapat berkumpul di halaman pelindung politik mereka. ${ }^{35}$

Keberhasilan Tarekat Sammaniyah mewarnai kehidupan masyarakat Palembang mendapat reaksi dari beberapa pihak. Reaksi ini memberi akibat yang efektif untuk kemunduran tarekat ini. Menurut Bruneissen, ada dua faktor yang menyebabkan kemunduran Tarekat Sammaniyah di Palembang. Perta-ma, perkembangan modernisasi Is-lam di satu sisi. Kedua, kecurigaan pihak keamanan di sisi lain. Keduanya mewarnai kehidupan masyarakat Palembang. Amalan juga dipakai untuk di luar pengikut tarekat antara lain bertujuan untuk kebe-basan dan kesaktian, sehingga ber-peran sebagai anti penjajah. Meski tentu saja amalan digunakan oleh para penjahat biasa dan kenyataan ini lah menimbulkan kecurigaan terhadap Tarekat Sammaniyah. ${ }^{36}$

Berdasarkan hasil penelusuran dan penelitian yang dilakukannya terkait eksistensi komunitas Tarekat Sammaniyah di Palembang itu sendiri sampai saat ini masih terus tumbuh subur dan memiliki pengikut yang jumlahnya sangat signifikan. Hal ini juga didukung dengan hasil penelitian Zulkifli yang menyatakan bahwa komunitas Tarekat Samman-iyah di Palembang memang tidak memiliki struktur organisasi secara formal, tetapi secara informal dan spiritual masing-masing komunitas tersebut menjalankan ajaran dan ritual tarekat sesuai tingkatan-tingkatannya.

Hal ini juga ditandai dengan digunakannya naskah al-Umwah al-wuthqá karya Shaykh 'Abd al-Samad sebagai pedoman yang sangat pen-ting bagi komunitas Tarekat Sam-maniyah di Palembang dalam melak-sanakan zikir, wirid dan pembacaan ratib Samman yang terus dilestarikan oleh para khalifah, guru atau murshid Tarekat Sammaniyah yang diikuti oleh para salik, murid dan pengikut komunitas tarekat tersebut hingga dewasa ini. Dari informasi ini dapat diketahui bahwa Tarekat Sam-maniyah di Palembang bukan saja mendapat perhatian yang sangat besar dari pada ulama Palembang itu sendiri bahkan Sultan Palembang juga memberikan perhatian dalam upaya pemeliharaan dan penyebaran ajaran Tarekat Sammaniyah di Palembang. ${ }^{37}$

Dari fenomena di atas, jika dikaji lebih dalam mengenai hu-bungan antara Kesultanan Palem-bang Darussalam dengan Tarekat Sammaniyah dapat digunakan teori pertukaran sosial.

\footnotetext{
35 Peeters, Jeroen, Ibid, hlm. 24.

${ }^{36}$ Yani, Zulkarnain, Op., Cit., hlm. 104.

37 Yani, Zulkarnain, Ibid., hlm. 107.
} 
Dalam Teori pertukaran sosial ini didasarkan pada pemikiran bahwa seseorang dapat mencapai satu pengertian mengenai sifat kompleks dari kelompok dengan mengkaji hubungan di antara dua orang (dydic relationship). Suatu kelompok dipertimbangkan untuk kumpulan dari hubungan antara dua partisipan tersebut. Perumusan tersebut mengasumsikan bahwa interaksi menusia melibatkan pertukaran barang dan jasa, dan bahwa biaya (cost) dan imbalan (reward) di-pahami dalam situasi yang akan disajikan untuk mendapatkan respon dari individuindividu selama inte-raksi sosial. ${ }^{38}$

Teori pertukaruan sosal di atas, menurut penulis hubungan antara Kesultanan Palembang dengan Tarekat Sammaniyah bukanlah melibatkan pertukaran barang dan jasa, dan bahwa biaya (cost) dan im-balan (reward) seperti yang diasum-sikan di atas.

Walaupun hubungan Kesul-tanan Palembang Darussalam dengan Tarekat Sammaniyah bersimbiosis (saling menguntungkan), akan tetapi hubungan keduanya lebih mengikat pada hubungan religious. Kesultanan Palembang merupakan pelindung tarekat di wilayah kesultanan agar sistem keagamaan di Palembang tetap berjalan, sedangkan Tarekat Sammaniyah sebagai elit masyarakat menjadi penggerak dari pengamalan agama Islam.

\section{PENUTUP}

Ketika para modernis meng-anggap kaum tarekat sebagai kaum yang membuat Islam pada kemunduran, kejumudan sebagai sumber bid'ah, takhayul dan khurafat. Namun hal tersebut tampak dinafi'kan oleh tarekat Sammaniyah yang diajarkan oleh Syaikh Abdul Shamad alPalembani untuk melakukan jihad fi sabilillah. Ini adalah bukti kuat bahwa mereka bukanlah sufi-sufi yang digambarkan kaum Muslim modernis. Kemudian penjelasan dan pemaparan mengenai "Peran Tarekat Samanniyah dalam Perang melawan Kolonial Belanda tahun 1819 di Palembang," di atas dapat ditarik kesimpulan.

Tarekat Sammaniyah yang berkembang di wilayah Kesultanan Palembang merupakan tarekat yang memiliki hubungan spesial dengan pihak Kesultanan Palembang. Se-hingga tidak mengherankan jika tarekat ini mampu berkembang pesat di Palembang. Tarekat Sammaniyah yang dibawa oleh Syaikh Abdul Shamad al-Palembani memiliki pengaruh besar dan peran penting dalam upaya perpolitikan melawan kolonial Belanda dengan ajaran jïhad fi sabilillah. Hal inilah yang menyebabkan Belanda terus mematai gerak-gerik Tarekat Sammaniyah. Selain itu, ajaran neo-sufisme yang diajarkan oleh Syaikh Abdul Shamad al-Palembani memberikan penye-garan baru umat Islam di Palembang.

38 Andy.tt:3 dalam jbptunikompp-gdl-andinurulb-23207-6-6teori-pdf di-akses pada 16 Desember 2013. 


\section{REFERENSI}

Abdullah, Taufik. 1979. Agama, Etos Kerja dan Perkembangan Ekonomi. Jakarta:1979

Abdurrahman, Dudung. 2011. Metode Penelitian Sejarah Islam. Yogyakarta: Ombak

Andy.tt. Teori-Teori dalam Komunikasi Kelompok dalam jbptunikompp-gdl-andinurulb-23207-6-6teoripdf di-akses pada 16 Desember 2013

Al-Kaf, Idrus. 2008. Tarekat dan Pemberdayaan Ekonomi Umat: Studi tentang Pemberdayaan Ekonomi Umat Tarekat Idrisiyah Pegendingan Tasikmalaya, dalam distertasi. Jakarta: UIN Syarif Hidayatullah

Azra, Azyumardi,1994. Jaringan Ulama Timur Tengah dan Kepulauan Nusantara Abad XVII dan XVII: Melacak. Akar-Akar Pembaharuan Pemikiran di Indonesia. Bandung:Mizan

Bruinessen, Martin Van. 1995. Kitab Kuning: Pesantren dan Tarekat. Badung: Mizan

Daliman, A. 2012. Metode penelitian Sejarah. Yogyakarta: Ombak

Hanaifah, Johan, 1999. Melayu-Jawa; Citra Budaya \& Sejarah Palembang. Jakarta: Raja Grapindo Persada

Huda, Nor. 2007. Islam Nusantara: Sejarah Sosial Intelektual Islam Indonesia. Yogyakarta: Ar-Ruzz Media

KHO Gadjahnata, Sri dan Edi Swasono. 1968. Masuk dan Berkembangnya Islam di Sumatera Selatan. Jakarta; UIN Press

Moleong, J.Lexy. 2001. Metodologi Penelitian Kualitatif. Bandung: Remaja Rosdakarya

Peeters, Jeroen. 1997. Kaum Tuo-Kaum Mudo: Socaial Religienze Verandering in Palembang. Terj. Sutan Maimoen. Jakarta: INIS

Solihin. 2005. Melacak Pemikiran Tasawuf di Nusatara. Jakarta: Raja Grafindo Persada

Tjandrasasmita, Uka. 2007. Pertumbuban dan Perkembangan Kota-kota Muslim di Indonesia: dari Abad XIII Sampai XVII Masehi. Kudus: Menara Kudus

Yani, Zulkarnain.2011. 'Al-Urwah al-Wuthqa: Tradisi dan Ritual Tarekat Sammaniyah diPalembang.Jakarta:Penamadani

Zulkifli dan Abdul Karim Nasution. 2001. Islam dalam Sejarab dan Budaya Masyarakat Sumatera Selatan. Palembang: Universitas Sriwijaya 